\title{
Avaliação da capaci dade de governo de uma secretaria estadual de saúde para o monitoramento e avaliação da Atenção Básica: lições relevantes
}

\author{
Evaluation of the capacity for governance of a State H ealth \\ Department in monitoring and evaluation of basic health care \\ provision - lessons learned
}

Juliana Sampaio ${ }^{1}$

Eduardo M aia Freese de Carvalho ${ }^{2}$

Gladys Fernanda Coelho Pereira ${ }^{3}$

Fernanda $\mathrm{M}$ aria Bezerra de $\mathrm{M} \mathrm{ello}^{4}$

${ }^{1}$ Universidade Federal de Campina Grande. Rua Juvêncio Arruda 795 , Bodocongó. 58407-495 Campina Grande PB. julianasmp@hotmail.com

${ }^{2}$ Centro de Pesquisas Aggeu

$M$ agalhães, Fundação

Oswaldo Cruz.

${ }^{3}$ Secretaria M unicipal de

Saúdede Recife.

${ }^{4}$ Secretaria M unicipal de

SaúdedeCaruaru.
Abstract The decentralization of the SUS requires state health departments to assume new powers as the monitoring and evaluation of Basic Care. This article aims to evaluate the "capacity for governance" of a State Health N ortheastern Brazilian Department in monitoring and evaluation of Basic Care. From the technical cooperation held via component III of Proesf, key health care managers were interviewed, strategical documents were analyzed, and participatory observation of activities was carried out at a training centre, with a "contend analysis" procedure. Among the results, are: absence of "government project", problems of physical infrastructure, human resources and material, with low professional qualification in the use of information systems, monitoring and evaluation, and strategic planning, promoting and fragile bureaucratic work use of epidemiological data. In 2006, the D epartment used federal resources to strengthen the monitoring and evaluation of primary care by expanding its physical infrastructure, acquiring equipment and training for staff, without investing its own resource. To conclude, the $\mathrm{Health}$ Department has experienced difficultiesin adjusting to decentralization, with the introduction of new working procedures into the institution. Key words Primary Care, M onitoring and evaluation, Capacity for governance
Resumo A descentralização do SUS exige que as secretarias estaduais desaúdeassumam novas competências como o monitoramento e avaliação da Atenção Básica. Este artigo busca avaliar a "capacidade de governo" de uma secretaria estadual de saúdedo $\mathrm{N}$ ordestebrasileiro para o monitoramento eavaliação da A tenção Básica. A partir da colaboração técnica realizada via componentellI do Programa de Expansão e Consolidação da Saúde da Família (Proesf), foram entrevistados gestores estratégicos, analisados documentos de gestão e realizada observação participativa das atividades do centro formador junto à secretaria, com "análise de conteúdo" do material disponível. Como resultados, destacam-se: ausência de "projeto de governo"; problemas de estrutura física, recursos humanos e materiais; profissi onais com baixa qualificação no uso de sistemas de informação, monitoramento e avaliação, e planejamento estratégico, promoven do trabal hos burocráticos e frágil uso de dados epidemiológicos. Em 2006, a secretaria usou recursos federais para fortalecer o monitoramento e avaliação da Atenção Básica, ampliando sua estrutura física, adquirindo equipamentos e capacitando pessoal, sem investir recurso próprio. Conclui-se que esta secretaria tem dificuldades em se adequar à descentralização, com a institucionalização de novos processos de trabalho.

Palavras-chave Atenção Básica, M onitoramento e avaliação, Capacidade de governo 
Introdução

Dentre as diretrizes estruturantes do Sistema Ú nico deSaúde(SUS), a descentral ização da atenção visa à redistribuição de poder eresponsabilidades entre as três esferas de governo ${ }^{1}$. Ela concretiza-se com a municipalização, buscando organizar a rede de saúde, a partir da capacidade de gestão de cada uma das esferas de governo².

Com a ampliação das responsabilidades dos municípios, os estados têm que assumir novas funções e competências, deixando de atuar na gestão dos serviços, principalmente da Atenção Básica $(A B)$. Além da prestação de serviços de saúde, foram municipalizados equipamentos, estruturas físicas erecursos financeiros. Estequadro interfere diretamente na capacidade de governo das secretarias estaduais de saúde (SES), que, além de uma redefinição defunções, seveem diante de um esvaziamento de recursos humanos e financeiros ${ }^{3}$.

N estecenário, verifica-sea necessidade deredefinição e fortalecimento do papel da gestão estadual no processo de descentralização. Deacordo com pactuações realizadas no Conselho $\mathrm{Na}$ cional deSecretários Estaduais deSaúde ${ }^{4}$, as principais responsabilidades da esfera estadual do SUS são: formulação de política, cooperação técnica, planejamento e programação, cofinanciamento, desenvolvimento derecursos humanose, por fim, avaliação e monitoramento $(M \& A)$.

Esse difícil processo é estruturante do mode lo proposto, portanto sua viabilização tem sido uma prioridade para o governo federal, nos últimos anos. Estados e municípios ainda apresentam dificuldades em assumir os novos papéis e funções e nem sempre tem sido possível descentralizar poderes e pactuar corresponsabilidades ${ }^{4}$.

Um exemplo do investimento empregado para fortalecer o processo de municipalização, consolidar $A B$ em âmbito municipal eenvolver 0 estado na gestão da $A B$, tem sido o Programa de Expansão e Consolidação da Saúde da Família (Proesf), do M inistério da Saúde, apoiado pelo Banco M undial (Bird) ${ }^{5}$. Este programa é dividido em três componentes, sendo o terceiro destinado ao fortal ecimento das funções dos gestores estaduais em relação ao $M \& A$ da $A B$. 0 intento maior é priorizar as atribuiç̧ões de formulação, planejamento, coordenação, controle e avaliação da gestão estadual como importante estratégi a para o aprimoramento do SUS, tendo por suposto seus princípios e diretrizes 5 .

A relevância desta iniciativa se dá na medida em que a área de avaliação em saúde no Brasil se encontra em estágio incipiente $e^{6,7}$, com pouco interesse dos gestores em saber os efeitos e impactos produzidos por suas políticas e projetos; e pouco conhecimento dos profissionais sobre métodos avaliativos.

O monitoramento e a avaliação são importantes ferramentas de planejamento e formulação de políticas e programas ${ }^{8,9}$, oferecendo ao gestor subsídios para uma visão crítica da realidade e para a tomada de decisão baseada em evidências ${ }^{10}$.

A avaliação, como julgamento de valor, e 0 monitoramento, como ferramenta degestão, são de suma importância para a tomada de decisões e/ou o planejamento de ações, programas e projetos, com vistas ao desenvolvimento de atividades compatíveis com a realidade, que garantam a qualidade dos serviços ${ }^{11,12}$.

Neste sentido, pesquisas têm sido financiadas para a avaliação dessas secretarias, buscando evidenciar suas capacidades edificuldades em assumir tais funções ${ }^{5}$. Este artigo é produto de uma dessas pesquisas que avaliou a capacidade de governo de uma SES para o $M \& A$ da $A B$. Ele permite, assim, elucidar questões que muitas vezes passam despercebidas pelos atores que estão envolvidos com o cotidiano das secretarias de saúde. Ao mesmo tempo, busca-se, a partir de uma experiência local, apontar entraves e estratégias do processo de fortalecimento da capacidade das SES, quevem orientando diversas ações e programas no país.

\section{Metodologia}

Para a avaliação, proposta foi utilizado como aporte teórico o Triângulo de Governo de Matus ${ }^{13}$, considerando suas três categorias de análise: projeto de governo, governabilidadee capacidade de governo.

O projeto de governo compreende principalmente o planejamento de ações com os objetivos de definir edirecionar prioridades. A governabilidade refere-se à capacidade do gestor de controlar as variáveis intervenientes, articulando 0 apoio e legitimidade política obtida. Por fim, a capacidade de governo é entendida como o conjunto de técnicas, métodos, destrezas ehabilidades de um gestor e de sua equipe para atingir os objetivos declarados ${ }^{14}$.

No estudo em questão, será focado o vértice do triângulo matusiano: capacidade de governo. Compreende-se, entretanto, que este só pode ser considerado em articulação com os vértices: go- 
vernabilidade e projeto de governo, que, desta forma, também serão considerados no presente artigo.

Ao mesmo tempo, serão utilizadas as contribuições de Freese et al. ${ }^{15}$ para a instrumental ização das categorias do Triângulo de Governo ao contexto do SUS. Para a análise da categoria Capacidade de Governo, os autores propõem identificar: (1) o perfil do gestor; (2) as características da gestão ( se centralizada ou descentralizada); e (3) as características do grupo de apoio. Para tanto, deve-se enfocar: (1) formação profissional (evidenciando a existência de especialistas em saúde pública, o número de profissionais envolvidos na equipe de governo e a capacitação e o treinamento da equipe de governo e demais profissionais de saúde); (2) a dinâmica do controle social; e (3) o nível do controle do secretário sobre o Fundo Estadual de Saúde.

Para dar conta da análise proposta, foi realizado, durante 2006, um estudo analítico transversal, com abordagem qualitativa. 0 estudo caracteriza-se ainda por ser de caso único, na medida em que esteve atrelado aos trabalhos de um centro colaborador (CC) no Plano de Institucionalização do $M \& A$ da $A B$ de uma SES, a partir do Proesf-componente III, sendo o referido estudo um dos principais produtos desta colaboração técnica.

Acompanhando as atividades do Proesf, o estudo em questão foi desenvolvido ao longo do ano de 2006, com profissionais da SES responsáveis pelo Proesf e/ ou pelo $M \& A$ da $A B$, com coletas de dados tanto na sede da SES quanto nos Núcleos Regionais de Saúde(NRS), distribuídos ao longo do território estadual. Assim, apesar de apresentar a experiência deapenas umaúnica SES no processo de institucionalização do $M \& A$ da $A B$, o presenteestudo permite o acompanhamento longitudinal de um processo que representou um dos principais investimentos do M inistério da Saúde no referido ano.

A SES em estudo situa-se num estado do N ordeste brasileiro, contando, atualmente com 1.213 equipes de Saúde da Família e/ou de agentes comunitários de saúde, além de 1.018 equipes de Saúde Bucal. Estes programas cobrem 100\% do território, oferecendo $80,99 \%$ de cobertura populacional. Ou seja, apesar de esses programas abrangerem todos os municípios do estado, nem toda a população é assistida por eles. No tocante aos recursos financeiros, 0 total do tesouro estadual desaúdeno ano de 2004 foi deR $\$$ 122.500.000,00. Destes, foram destinados R\$ 2.293.000,00 para a Atenção Básica, o que repre- senta 2,39\%, não estando definidos recursos específicos para monitoramento e avaliação.

Outras informações relevantes sobre a SES em estudo serão apresentadas ao longo do artigo contextualizando os dados encontrados.

A natureza dialética e processual da teoria de base deste estudo (Triângulo de Governo) sugeriu, ainda, uma triangulação metodológica ${ }^{16,17}$, a qual multiplica as tentativas de abordagem, consolidando várias fontes de informações. Assim, foram utilizados os seguintes métodos:

1. Entrevistas semiestruturadas - aplicadas a uma amostra composta por conveniência pelos atores que apresentam função estratégica dentro da SES, em relação ao processo de fortalecimento do $M \& A$ : a secretária executiva de saúde, a coordenadora estadual da $A B, 0$ coordenador do Proesf, um representante de quatro dos doze núcleos regionais de saúde (NRS) e a coordenadora da vigilância epidemiológica (membro atuante no grupo coordenador do $M \& A$ da $A B$ na $\mathrm{SES})$. As entrevistas versaram sobre os seguintes temas: grau de conhecimento acerca de $M \& A$ dos técnicos da SES responsáveis pela institucionalização do $M \& A$ da $A B$; grau de comprometimento desses gestores com o $M \& A$ da $A B$; dificuldades políticas e de gestão identificadas para o $M \& A$ da AB; grau de autonomia desses gestores; participação do controle social no processo de institucionalização do $M \& A$ da $A B$ enível de priorização do $M \& A$ da $A B$ na SES.

2. Análisedocumental - foram analisados: (a) o organograma da SES; (b) o Cadastro Nacional de Estabelecimentos de Saúde (CNES); (c) o Sistema de Controle (Sisco), o Plano Orçamentário Anual (POA), o Quadro de Detalhamento de Despesas (QDD), atas de reuniões do Grupo Coordenador e relatórios do Centro Colaborador. Estes documentos são importantes fontes de informações acerca da organização da SES e do seu grau de priorização do $M \& A$ da $A B$. A partir deles, buscou-se identificar: as funções e atribuições dos diversos setores da secretaria; os recursos financeiros investidos ou previstos para institucionalização do $M \& A$ da $A B$ ea existência de políticas e/ou programas de institucionalização do $M \& A$ da $A B$ na SES.

3. O bservação partici pativa - realizada nas atividades do Centro Colaborador (CC) do Plano de Institucionalização do $M \& A$ da $A B$ na SES, contratado a partir do incentivo do Proesf. Os pesquisadores do presente estudo fizeram parte de todo o processo de trabalho e intervenção do CC naSES. Participaram, assim, de oficinas, reuniões, visitas, eventos e fóruns regionais. As ob- 
servações foram registradas num "diário de campo"17 e depois sistematizadas, a partir dos objetivos do estudo.

A análise dos dados foi baseada no método de analise de conteúdo ${ }^{18}$, a partir de um conjunto de técnicas que visa à descrição do conteúdo das mensagens, apresentando os seguintes passos: ordenação dos dados, classificação dos dados eanálisefinal, com interpretação das categorias de análises.

Este estudo foi aprovado por um Comitê de Ética em Pesquisa (CEP), eos sujeitos envolvidos assinaram o termo de consentimento livre e esclarecido. Para garantir o enquadramento ético, neste artigo não será i identificada a SES avaliada. Buscou-se, com isto, evitar conflitos de interesses que expusessem os gestores locais, o que poderia ter repercussões sobre suas atuações institucionais. Acredita-se, ainda, que tal identificação é dispensável, já que o artigo fornece apenas um exemplo que permita oferecer lições importantes, a partir da reflexão sobre as dificuldadese potencialidades das SES no processo de institucionalização do $M \& A$ da $A B$.

\section{Resultados ediscussão}

Como proposta de sistematização e apresentação dos principais resultados encontrados, temse 0 esquema da Figura 1, buscando articular os critérios de avaliação proposto por Freese et al..$^{15}$ para a "capacidade de governo", com o contexto da SES e os principais efeitos daí decorrentes. Acreditando que um estudo de caso pode trazer lições relevantes para outras experiências, foram ainda identificadas algumas questões a serem consideradas por qualquer gestor que se ocupe dessa problemática.

Para discussão dos resultados, eles serão apre sentados a partir das categorias construídas na análise de conteúdo realizada. As categorias foram definidas de acordo com os diferentes grupos/atores estratégicos para o $M \& A$ da $A B$. Para cada grupo/categoria pôde ser identificado um conjunto de problemas enfrentados, que tem impactos diretos na capacidade de governo para o $M \& A$ da $A B$.

O perfil do secretário de saúde e a dinâmica do nível central da SES

Nos últimos quatro anos, a gestão da SES foi marcada por mudanças de secretários, que apesar de não representarem para os entrevistados uma descontinuidade de trabalho, parecem ter corroborado a inexistência de um plano de governo oficial que oriente as ações desenvolvidas pela secretaria, mais especificamente pela coordenação da AB. Asfrequentes mudanças da direção deuma organização interferem negativamente na sua condução ${ }^{19}$, e consequentementena capacidade de governo da gestão, pois enfraquecem o grupo de apoio, uma vez que repercutem não apenas na sua liderança, mas também na definição dos perfis e da quantidade de profissionais que a organização necessita, prejudicando, assim, a política de gestão de pessoas.

Outro fato relevante é que o organograma oficial encontra-se desatualizado, não correspondendo à prática desenvolvida. N ele, não há um setor específico para a gerência da $A B$, nem para a coordenação de vigilância ambiental ou para o planejamento, sendo esteúltimo inserido naunidade setorial de administração. Na prática, a coordenação de $A B$ é uma assessoria de gabinete do secretário, apesar defuncionar como uma das coordenações estratégicas da SES.

Essa coordenação é ligada diretamente ao gabinete, ela tem status de coordenação sem estar na estrutura organizacional. A genteespera quea próxima gestão comece a ver a $A B$ como estruturante para a saúde (Ent. 1).

Considerando as contribuições de $\mathrm{Matus}^{20}$, os três vértices do Triângulo de Governo - governabilidade, capacidade de governo e projeto degoverno - secondicionam mutuamente. Desta forma, pode-se compreender que a ausência do projeto de governo da secretaria tem repercussões diretas na sua capacidade de governar. A indefinição da missão organizacional, segundo Rivera ${ }^{21}$, implica a impossibilidade de definir as funções internas, o que fragiliza a capacidade de governo da gestão.

Considerando o contexto nacional de redefinição das funções das SES, é importante considerar que a fragilidade nos planos estaduais de saúde pode ser reflexo das dificuldades enfrentadas pelas SES, porém parece agravar ainda mais 0 atual cenário. Torna-se relevante, assim, criar estratégias para a reconstrução e/ou apropriação dos planos estaduais de saúde como instrumentos norteadores das ações das SES, definindo as necessidades para uma política de desenvolvimento institucional.

Buscando identificar o perfil do gestor, um dos critérios de análise da capacidade de governo ${ }^{19}$, é importante salientar que 0 atual secretário da SES em foco é avaliado positivamente pelos atores entrevistados. Esta avaliação é justifi- 


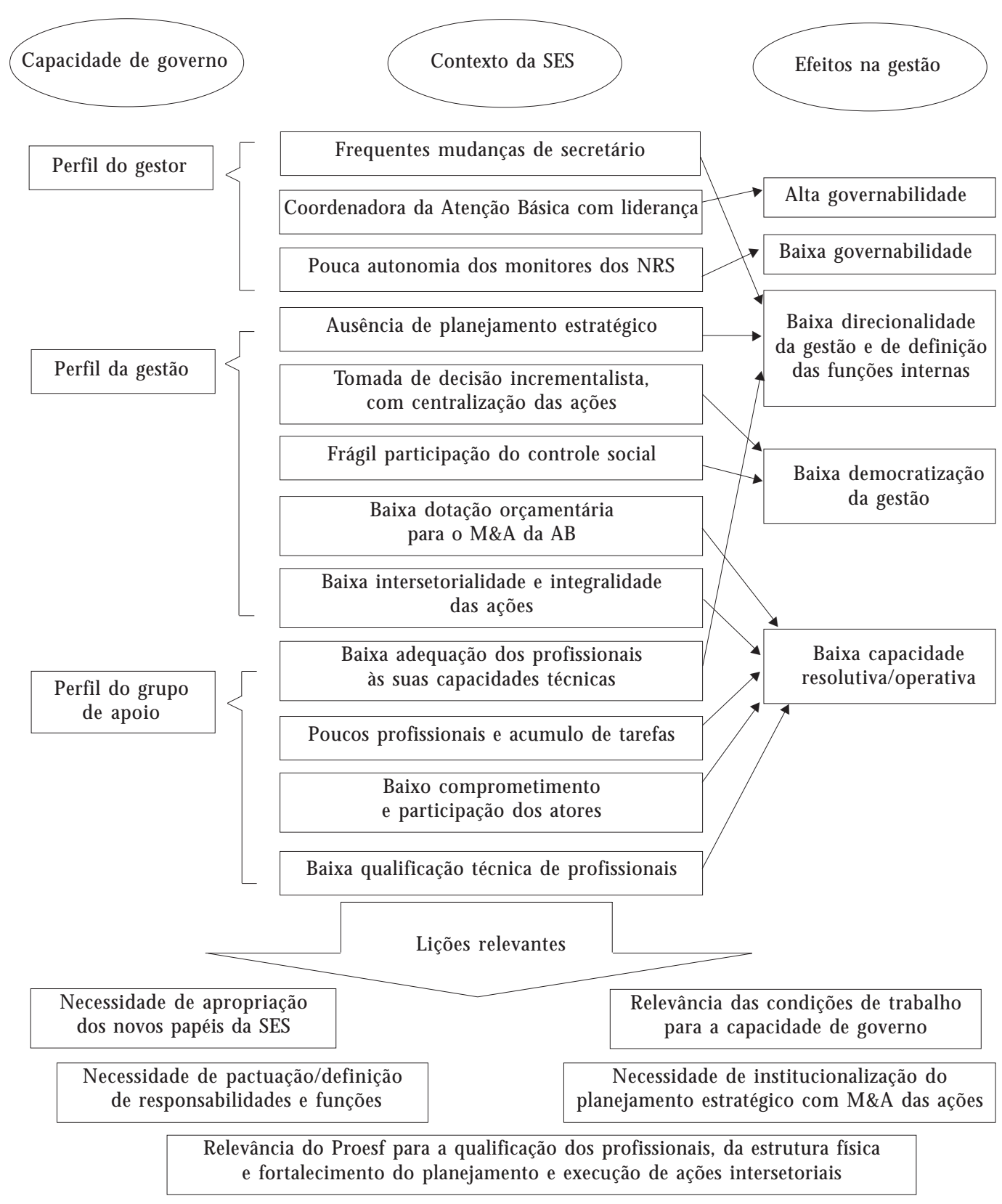

Figura 1. Articulação dos critérios de capacidade de governo com contexto da SES: efeitos e lições decorrentes.

cada pelo fato de ele garantir espaços de escuta e pactuação, tanto com seu grupo gestor, composto pelas principais coordenações da secretaria, quanto com os superintendentes e gestores de hospi- tais, acreditando serem estes os atores mais estratégi cos para o fortalecimento das ações da SES. Esta escuta é avaliada pelos entrevistados como reflexo deuma gestão mais democratizada, o que 
Ihe garante legitimidade diante do grupo, com fortalecimento da base de apoio, ampliando, consequentemente, sua governabilidade.

A mesma condução que ele está dando aqui no nível central, com outros coordenadores do grupo gestor, ele está procurando ter a mesma relação de entendimento, de resolução do problema, de ouvir, de atender aos superintendentes e gestores de hospital (Ent. 3).

Segundo Rivera ${ }^{22}$, a governabilidade pode ser expressa através da distribuição do poder administrativo e das funções nos diversos níveis organizativos. Entretanto, observa-se que os atores priorizados nesses espaços de escuta não são, necessariamente, os responsáveis pela Atenção Básica, o que parece evidenciar que ela não éalvo de tal proposta de democratização dos espaços de debate.

Ao mesmo tempo, promover espaços de escuta dos diversos atores não garante que o poder decisório seja compartilhado, o que segundo Araújo e $\mathrm{M}$ acie ${ }^{23}$ caracterizaria uma forma de tomada de decisão pluralista; e que de acordo como Freese et al. ${ }^{15}$, correspondendo ao caráter mais ou menos democrático de uma gestão, é um importante critério de capacidade de governo.

Vale destacar que os espaços de escuta e diálogo não têm possibilitado a construção coletiva de um projeto de governo, com a formulação de políticas estrategicamente planejadas. Ao contrário, as ações são desenvolvidas de acordo com as necessidades que surgem, o que parece marcar um perfil incremental ista das políticas públicas ${ }^{24}$.

Ainda como característica de uma gestão elitista ${ }^{24}$, marcado pela centralização do poder decisório a uma elite restrita de atores, o que repercute negativamente na capacidade de governo, evidencia-se que a gestão não investe na pactuação com outros atores representantes das esferas de controle social e/ou os demais profissionais de saúde. Segundo Freese et al. ${ }^{15}$, a participação do controlesocial na gestão éum importante critério de avaliação da capacidade de governo, demonstrando seu perfil mais ou menos democrático. N este aspecto, a coordenadora da AB julga que 0 Consel ho Estadual de Saúde não exerce sua função de maneira adequada, afirmando que numerosas tentativas de reuniões foram realizadas e fracassadas por falta de quorum. Esta fragilidade do controle social repercute na proposta metodológica da SES para a institucionalização do $M \& A$ da $A B$, quejáno final desua execução ainda não havia sido aprovada pelo referido conselho.

A proposta metodológica, aqui, do nosso plano, já foi adiada, não sei quantas vezes, porque não tem quorum... Ninguém nunca vem aqui saber 0 queaconteceu com o Proesf, o porquêdesse dinheiro (Ent. 1).

A centralização do poder dentro da organização tem repercussões diretas na sua capacidade de governo. Este fato pode ser ilustrado com a centralização, na secretaria da administração do governo do estado, dos processos de compras e licitações, o que, ao burocratizar a aquisição dos equipamentos e insumos, dificulta a operacionalização do Proesf, segundo seu coordenador. Para Araújo e $M$ aciel ${ }^{23}$, essa centralização é caracterizada como tomada de decisão elitista, em que apenas um grupo é responsável pela decisão econtrole da política.

Neste ponto é possível fazer uma avaliação dos resultados do Proesf, uma vez que a intervenção do centro colaborador (CC) viabilizou espaços de construção coletiva, possibilitando, segundo os entrevistados, uma inusitada experiência de planejamento estratégico ${ }^{25}$. Foi possível definir ações estratégicas para o $M \& A d a A B$, identificar sua relevância para os diferentes atores e delimitar responsáveis para sua execução. Segundo Kopf e Hortale ${ }^{26}$, para a adequação das organizaçõesénecessário queelas tornem-semais flexíveis e descentralizem seu poder decisório, democratizando-o a partir da participação efetiva deprofissionais e usuários na sua condução. Vale lembrar que a descentralização da gestão é um dos critérios para avaliação da capacidade de governo proposto por Freese et al. ${ }^{15}$.

\section{O perfil do grupo coordenador}

Com o objetivo de dar respaldo político ao projeto de institucionalização do $M \& A$ da $A B, 0$ Proesf previu a constituição de um grupo coordenador (GC) dentro da SES, com caráter técnico-consultivo ${ }^{5}$. No caso em estudo, o GC foi constituído pelas chefias dos seguintes setores: Secretaria Executiva da Saúde, Coordenação de AB, Coordenação deVigilância Epidemiológica, Coordenação de Promoção da Saúde da M ulher, da Criança eAdolescente, Coordenação de Planejamento, Coordenação de Vigilância Ambiental, Coordenação de Controle e Avaliação, Coordenação de Assistência à Saúde.

Quanto ao perfil profissional desta equipe, critério de avaliação da capacidade de governo ${ }^{15}$, deve-se destacar que entre seus oito membros há seis médicos, uma psicóloga e um odontólogo; dos quais seistêm pós-graduação (cinco em Saúde Coletiva e áreas afins). Percebe-se, assim, que o referido grupo tem qualificação diversa, o que 
permite ampliar seu campo de atuação (capacidade de governo), oferecendo maior poder de controle diante das variáveis intervenientes (governabilidade), com vistas a fortalecer o Plano de Institucionalização do $M \& A$ da $A B$ - Proesf (projeto de governo).

M as para compreender melhor a capacidade de governo deste grupo, deve ser ressaltado que ele sofreu dificuldades para sua operacionalização. Segundo as entrevistas e observações, o referido grupo não conseguiu garantir sistematização de reuniões, com representatividade dos diversos setores. A condução do $M \& A$ da $A B$ ficou restrita basicamente a três representações: secretaria executiva, coordenação de AB e coordenação de vigilância epidemiológica, estando os demais setores numa posição periférica no processo. Por conseguinte, o gerente do Proesf passou a executar ações que, a priori, deveriam ser pactuadas dentro do grupo, tornando-se responsável pela elaboração do Plano O perativo Anual (POA) do Plano de Institucionalização do $M \& A$ da $A B$ e por sua apresentação na Comissão Intergestora Bipartite $(\mathrm{ClB})$, sob supervisão da coordenadora da AB.

Determinadas coisas que vêm para eu decidir era para estar sendo decididas por esse grupo. $\mathrm{E}$ a proposta metodológica passa na CIB. Quem deve estar apresentando a proposta era para ser uma pessoa do núcleo coordenador, mas quem vai apre sentar sou eu (Ent. 2).

0 pouco comprometimento de alguns membros do grupo coordenador foi justificado pela baixa valorização dada ao Plano de Institucionalização do $M \& A$ da $A B$ por parte dos diversos setores da secretaria. Este évisto como uma responsabilidade da Coordenação da $A B$, o que marca a desarticulação das ações e dos projetos na SES.

Este quadro contribuiu para o enfraquecimento da capacidade gerencial do grupo, pois, segundo Rivera et al. ${ }^{27}$, a articulação entre os diversos atores possibilita a ampliação das competências disponíveis, facilitando a condução do projeto de governo, o que tem diretas consequências na capacidade de governo da gestão.

M esmo com tais dificuldades, a conformação do GC permitiu articulações entre algumas coordenações da secretaria, que apesar de pontuais e restritas à implantação do plano de $M \& A$ da $A B$ são avaliadas como um avanço para a dinâmica da secretaria. Este dado vem mais uma vez demonstrar a relevância do Proesf na proposição de novas práticas gerenciais na SES.

Ainda com referência ao perfil dos gestores, é evidente que, em relação ao $M \& A$, a pessoa reco- nhecida na SES por ter maior poder decisório éa coordenadora da $A B$, vista como a principal responsável pelo Plano de Institucionalização. Essa legitimação política é justificada por sua capacidade de condução do processo, resultante de sua experiência profissional em gestão estadual e municipal, e da própria exigência de sua função ante a Coordenação daAB. Percebe-se, maisuma vez, a compreensão do Plano de Institucionalização como uma proposta exclusiva da coordenação da $A B$ e não como um projeto de governo, priorizado por toda a gestão. Este fato deve servir de alerta aos gestores em saúde, na medida em que evidencia que quando um projeto não é tomado como uma prioridade da gestão, por mais recursos que disponibilize, poderá ter seu sucesso comprometido.

Observa-se, assim, que a priori o grupo coordenador é dotado de capacidade de governo. Entretanto, considerando a inter-relação dos vértices do Triângulo de Governo ${ }^{13}$, a capacidade de governo pode ser comprometida pela fragilidade na governabilidade do grupo ou pela ausência de um plano de governo. 0 que cabe salientar é que muitas vezes uma SES dispõe de uma equipe técnica capacitada, entretanto, fragilmenteorganizada e articulada. D essa forma, deve-se considerar que nem sempre a solução de entraves encontra-se em processos de capacitação de pessoal, mas sim em processos de planejamentos estratégicos ${ }^{28}$ que possam trabalhar os três vértices do triângulo matusiano.

0 perfil da equipe técnica

da coordenação da AB

A coordenação da AB é constituída pela coordenadora, quatro monitoras das macrorregionais, um assessor de informação, dois monitores de saúde bucal, quatro técnicos das áreas temáticas e o coordenador do Proesf. No cotidiano das relações institucionais, os doze monitores da AB dos NRS não são identificados como pertencentes à equipe da coordenação da $A B$ da SES, apesar de serem os atores que operacionalizam as ações da coordenação junto aos municípios. Esta diferenciação parece Ihes resguardar uma posição hierárquica inferior em relação aos técnicos lotados no nível central da SES. Pode-se supor que esta hierarquização tende a fragmentar o grupo, acirrando as rivalidades internas, dificultando as relações de trabal ho e, consequentemente, a capacidade operativa do grupo.

A fragmentação do grupo reflete, assim, os processos de trabalho instituídos. Não foi possí- 
vel evidenciar um plano de ação da coordenação que permitisse a integração das ações desenvolvidas. Cada profissional desenvolve suas próprias atividades demaneira desarticulada, o quetem direta repercussão na capacidade de governo da gestão. As ações desarticuladas reforçam processos de trabalho fragmentados, com baixa capacidade resolutiva ${ }^{20}$.

Ao mesmo tempo, a promoção de processos de planejamento estratégico possibilita maior descentralização do poder decisório, permitindo que cada nível organizacional se ocupe de problemas adequados ao seu poder resolutivo ${ }^{28}$. Quanto menos hierarquizada a gestão, maior será a integração entre as pessoas envolvidas e, consequentemente, maior será a capacidade de resolução das variáveis intervenientes ${ }^{27}$. Percebe se aqui, mais uma vez, a relevância da descentralização de responsabilidades e a adequação das competências aos diferentes níveis organizacionais para a resolução de problemas, fortalecendo a governabilidade dos diversos atores ${ }^{23}$.

Quanto ao perfil do grupo de apoio da coordenaçãa ${ }^{19}$, deve ser destacado que, segundo a coordenadora da $A B$, cerca de $70 \%$ do grupo tem formação sanitarista. Entretanto, considerando as fichas de inscrição do Curso de Aperfeiçoamento em $M \& A$ da $A B$, oferecido pelo $C C$, observa-se que os técnicos da AB da SES têm formação nas áreas de saúde, administração e licenciatura em história; mas apenas aproximadamente 20\% deles referem ter pós-graduação em Saúde Pública, não sendo possível garantir a existência de especialização dos demais técnicos. Ainda de acordo com a coordenadora da AB, $90 \%$ do grupo já exercia suas atividades antes dessa gestão.

Ao assumir seu cargo, a coordenadora inseriu outros técnicos, com experiências acumuladas, no grupo. Entretanto, os novos atores foram aceitos com resistência, o que gerou rivalidade entre os membros da equipe. A chegada da própria coordenadora foi permeada por dificuldades.

Aí quando eu vi ela, disse: "M eu Jesus, eagora? Essa mulher!" Eu tinha uma imagem horrível... M as foi outro nível de trabalho (Ent. 4).

A confiança foi conquistada a partir da proposição de novas formas de trabalho, com ampliação dos espaços de discussão entre os técnicos e a coordenação. Atualmente, a coordenadora dispõe não apenas do apoio e colaboração de todos como também da credibilidade e da legitimidade em relação aos núcleos.

Esses dados evidenciam que a capacidade de liderançaéuma prerrogativa de extrema relevância para coordenar um grupo com efetividade ${ }^{28}$.
Ao mesmo tempo, o fomento de espaços de discussão epactuação fortaleceu o respaldo político da coordenadora dentro da SES, em especial com os técnicos de sua equipe e dos NRS. O perfil da gestora favoreceu a organização da equipe, o gerenciamento das ações e consequentemente a ampliação da capacidade de ação do grupo, evidenciando a relevância do perfil dos gestores para a ampliação da capacidade de governo ${ }^{20}$.

Por fim, deve-se compreender que a capacidade de uma gestão pode ser comprometida pelas condições de trabalho em que os atores estão inseridos. Neste sentido, é relevante considerar quais as estruturas disponíveis para que sejam desenvolvidas as habilidades desejadas.

$\mathrm{Na}$ observação participante, puderam ser identificadas as precárias condições da estrutura física em que se encontrava a coordenação da $A B$ do nível central da Secretaria Estadual de Saúde pesquisada, no início da implantação do Proesf. Os técnicos estavam alojados numa sala com paredes mofadas e com infiltrações, havia carência de equipamentos de informática, de acesso à Internet e de insumos em geral. Considerando as contribuições de Freese et al. ${ }^{15}$, compreende-se quesem estrutura física e equi pamentos adequados a gestão tem sua capacidade de governo enfraquecida, na medida em que tais condições interferem na capacidade produtiva do grupo.

Nós não tínhamos nenhum equipamento de apoio, audiovisual, retroprojetor, nem projetor de slide, muito menos datashow. Os computadores estavam sucateados, estrutura digna realmente de você dizer assim: "Não tenho ambiente saudável de trabalho" (Ent. 1).

Com recursos do Proesf, a coordenação da $A B$ reformou sua estruturafísica eadquiriu equipamentos, o que segundo a equipe viabilizou ações até então não desenvolvidas por falta de condições materiais existentes. Este fato evidencia, mais uma vez, a relevância do Proesf para a ampliação da capacidade de governo da SES.

Vale salientar que, segundo o coordenador do Proesf, o único recurso financeiro disponibilizado para o incremento da $A B$ é o recurso do Proesf, estimado em cerca de $R \$ 1.368 .000$ (um miIhão e trezentos e sessenta e oito mil reais) para dois anos. É relevante ainda registrar que não há investimentos do tesouro estadual de saúde para fortalecer a institucionalização do $M \& A$ da $A B$, nem mesmo para a ampliação da capacidade de governo dos NRS e/ou dos municípios, seja com incremento da estrutura física, seja com desenvolvimento dos recursos humanos. Esteé um resultado preocupante, pois evidencia o frágil com- 
prometimento do gestor estadual com o $M \& A$ da $A B$, estando 0 aporte financeiro sob responsabilidade exclusiva da esfera federal. Isto interfere negativamentenos resultados do programa, além de não Ihe garantir sustentabilidade.

O perfil dos técnicos

e as dinâmicas dos NRS

Dentre os entraves identificados na capacidade degoverno dos NRS, deve-seapontar o acúmulo de trabalho para poucos técnicos disponíveis. 0 estado possui mais de duzentos municípios, dos quais $64 \%$ têm menos de dez mil habitantes. Desta forma, deve-se considerar que a maioria dos municípios é de pequeno porte, 0 que parece demandar maior apoio da esfera estadual. O u seja, além do grande volume de municípios, estes ainda são extremamente demandantes das funções atualmente propostas para a gestão estadual ${ }^{4}$, em especial de apoio técnico e monitoramento e avaliação.

Por sua vez, a SES em questão - organizada a partir do Plano Diretor de Regional ização (PDR) e da N orma Operacional de Assistência à Saúde ( $N$ oas $01 / 02)^{29}$ - tem seus NRS com distribuição desigual de municípios, o que permite que um NRS seja responsável por sete municípios, enquanto outro é responsável por 42. Esta distribuição diferenciada dificulta o processo de trabalho, sobrecarregando alguns técnicos, o que tem direta repercussão na qualidade de suas produções e na capacidade de governo da SES.

Um segundo entrave diz respeito à organização do processo de trabalho, à habilidade técnica dos profissionais e à cultura organizacional instituída. Neste sentido, deve ser pontuada a necessidade de melhor adequação dos profissionais às suas reais capacidades técnicas, redefinindo funções ${ }^{27}$. A fragilidade na implantação de processos de trabalho estrategicamente planejados e coletivamente operacionalizados transforma-se num entrave para a institucionalização do $M \& A$ da $A B$ naSES, na medida em que, como afirma Toni ${ }^{30}, A$ grandequestão consiste em saber se somos arrastados pelo ritmo dos acontecimentos do dia a dia, como a força da correnteza deum rio, ou sesabemos aondechegar econcentramos nossas forças em uma direção definida.

Finalmente, como terceiro en trave podem ser apontadas as relações de poder instituídas dentro da secretaria. Compreende-se, aqui, o poder como inerente a todo e qualquer tido de relação interpessoal e, consequentemente, institucional. Para Bourdieu ${ }^{31}$, o poder se estrutura dentro de campos de forças, ou seja, espaços onde são tra- vados jogos de poder entre agentes - sujeitos e instituições. Estes possuem capitais (econômicos, sociais esimbólicos) diferentes elutam para ampliá-los ou mantêlos.

As relações de poder interferem, assim, nacapacidade de governo de uma gestão, na medida em que modulam as capacidades de ação dos diferentes atores. Na secretaria em foco, observa-se que a diferenciação entre os membros da equipe da $A B$ reflete-se na incipiente autonomia dos monitores da $A B$ dos NRS para a aquisição de insumos necessários para viabilizar, satisfatoriamente, seus processos de trabalho. Por falta de recursos, os monitores que têm como principal atividadeo acompanhamento ea cooperação técnica junto aos municípios, funções estratégias da SES na Aten ção Básica ${ }^{4}$, não conseguem se deslocar até eles. Assim, suas atividades ficam restritas ao repasse de informações e de documentos.

Tem a questão da autoestima que cai muito, porque não tem um ambiente de trabalho muito bom. Atéa gente não dá credibilidade (Ent. 8).

A pesar de as fragilidades dos NRS serem reconhecidas, com o recurso do Proesf apenas um NRS foi reestruturado. Em contrapartida, a gestão estadual passou a garantir o repasse de recurso mensal que, apesar de não estar destinado especificamentepara o $M \& A$ da $A B$, possibilita o pagamento de despesas com diárias dos NRS. Ainda com os recursos do Proesf está prevista a compra de um computador com impressora para cada NRS, mas estes ainda não foram adquiridos, ea coordenadora da $A B$ receia queeles, depois de comprados, não sejam direcionados aos N RS. Este resultado evidencia o pouco poder institucional dos NRS, bem como o baixo comprometimento dos gestores desta secretaria com o $M \& A$ da $A B$, parecendo ser apenas receptíveis ao Proesf e seus recursos.

Por sua vez, a atuação do CC favoreceu a problematização da função técnica dos gerentes da AB. 0 grupo passou a questionar seu papel de gestor público, identificando como funções da esfera estadual: cooperação técnica aos municípios, planejamento, monitoramento e avaliação. Com a redefinição desses papéis, os atores puderam assumir novos processos de trabalho, ampliando sua capacidade de intervenção em problemas demaior complexidade. Segundo M atus ${ }^{25}$, a descentralização do poder decisório permiteque cada nível gerencial se ocupe dos problemas que Ihes parecem com maior valor. Isto torna a gestão menos hierarquizada, possibilitando maior engajamento dos atores, refletindo na criatividade ecapacidade resolutiva deles. 
Quando eu cheguei, encontrei pessoas de nível superior capacitadas, com especialização, queeram como tel efonistas. Eu chamava de telegirls porque estavam mais tempo dando informações por tele fone do quemesmo contribuindo na gestão estadual (Ent. 1).

Os espaços de discussão instituídos na coordenação da $A B$ favoreceram a descentralização de responsabilidades e a redefinição das funções dos técnicos, em especial dos NRS, promovendo o empoderamento desses atores. A ponta-se como lição desta experiência que, assumindo de forma autônoma e crítica suas funções, os técnicos da coordenação da $A B$ e dos NRS perceberam-se como atores estratégicos eimplicados na institucionalização do $M \& A$ da $A B$, tornando-se próativos no desempenho de suas atividades, o que é fundamental para a consolidação de uma gestão estrategicamente planejada ${ }^{20}$. Ao mesmo tempo, a participação dos diversos atores permite que o projeto de governo ganhe legitimidade política, descentraliza-o dos poderes decisóriose amplia a base de apoio ${ }^{13}$.

Seguindo a avaliação da capacidade de governo, no que se refere ao perfil da equipe de apoio ao gestor ${ }^{19}$, deve-se salientar que alguns possuem pós-graduação e a grande maioria tem experiência anterior em gestão pública. Entretanto, a análise de um teste realizado no Curso de A perfeiçoamento em $M \& A$ da $A B$, oferecido pelo $C C$, aponta que os técnicos da $A B$ da SES têm dificuldade em trabal har com sistemas de informação e planejamento, além de desconhecerem a importância do $M \& A$ para a $A B$ e do papel da SES ante a AB. Ao mesmo tempo, tais profissionais têm dificuldades de trabalhar com sistemas de informação e com o próprio computador, 0 que foi identificado pelos entrevistados como uma grande dificuldade para o desempenho de suas atividades.

O bserva-sequea fragilidadeno conhecimento técnico acerca dessas atividades tem potencializado os trabalhos burocráticos e o repasse de documentos, impossibilitado os monitores dos NRS de desempenharem suas atividades de gestão estadual, tais como: planejamento, monitoramento, avaliação e cooperação técnica junto aos municípios. Desta forma, pode-se concluir que, de fato, a fragilidade técnica dos profissionais dos NRS é um fator de grande relevância para a capaci dade degoverno, na medida em que inviabiliza o desenvolvimento das funções específicas da instituição.

M ais uma vez, pode-se apontar a relevância do Proesf para a institucionalização do $M \& A$ da $A B$ na SES, na medida em que viabilizou o Curso
deA perfeiçoamento em $M \& A$ da $A B$, oferecido a cinquenta técnicos da SES, em especial à equipe da coordenação daAB do nível central edosNRS, além de membros do $\mathrm{GC}$ etécnicos da vigilância em saúde. Segundo os relatórios do CC, as avaliações do referido curso foram positivas, sendo salientada a relevância dos temas trabalhados e 0 aprendizado resultante.

Em contrapartida, observa-se neste caso em estudo um problema também identificado em outras secretarias de saúde, estaduais e municipais do paí $3^{32}$, sendo percebida a necessidade de implantação de uma política degestão depessoas que possibilite: (1) a contratação de novos quadros profissionais, diminuindo a sobrecarga de trabalho da equipeexistente; (2) readequação dos profissionais existentes em funções compatíveis com sua capacidade técnica e perfil profissional; (3) promoção do permanente aperfeiçoamento técnico dos profissionais, organizando/racionalizando as ofertas de cursos e treinamentos.

Observa-seassim queépreciso construir uma política de desenvolvimento de pessoal, que viabilize o permanente aperfeiçoamento técnico, via cursos presenciais ou a distância, com "aprendizagem significativa", produzida a partir dos problemas enfrentados no cotidiano, considerando as experiências e saberes dos diversos atores ${ }^{33}$.

0 perfil

das secretarias municipais de saúde

Os municípios são estratégicos para o $M \& A$, pois são os reais implementadores da $A B$. São eles que produzem todos os dados da saúde que devem ser monitorados². Entretanto, observa-se no caso em estudo queosmunicípios, em especial os de pequeno porte, apresentam uma série de dificuldades para o $M \& A$ da AB. Uma dessas dificuldades diz respeito à falta depessoal especializado, além do acúmulo de várias funções dos atores disponíveis. Em alguns casos, a ausência de pessoal qualificado faz com que gestores municipais paguem consultores para realizarem tarefas que deveriam estar institucionalizadas, como, por exemplo, avaliação de indicadores, ou mesmo a construção de projetos institucionais.

Os dados coletados ainda evidenciam que, no âmbito das secretarias municipais, há fragilidade na análise dos dados epidemiológicos/gerenciais, dificultando que a informação seja instrumento de auxílio para a tomada de decisão em saúde. Os técnicos dos municípios, em sua grande maioria, segundo os monitores da $A B$ dos NRS, limitamse ao repasse e armazenamento de dados, sem transformá-los em informação. 
Segundo Branco ${ }^{34}$, o uso dos sistemas de informação em saúde para a construção de indicadores de avaliação, planejamento e acompanhamento pode ser considerado insuficiente devido a vários fatores, dentreeles: o inci piente conhecimento dos gestores e profissionais de saúde; a relevância que lhes é atribuída na tomada de decisão; e a carência de infraestrutura tecnológica e de capacitação de recursos humanos.

É ainda apontada a dificuldade de os municípios formarem um corpo técnico qualificado, devido ao incipienteincentivo à interiorização de profissionais para executar o $M \& A$ da $A B$, tanto no nível dos NRS quanto no dos municípios.

$\mathrm{N}$ ão existe assi $\mathrm{m}$ uma política direcionada aos recursos humanos que incentive mais, que atraia o profissional para o interior do Estado (Ent. 3).

Esse conjunto de dificuldades enfrentadas pe los municípiospara a institucionalização do $M \& A$ da $A B$ reforça a relevância da esfera estadual na construção de políticas públicas que possibilitem o fortalecimento das SMS. Com o processo de descentralização do SUS, é dever do gestor estadual zelar para que os municípios em seu território possam assumir suas funções, com eficiência, com vistas ao fortalecimento do sistema de saúde e ampliação da qualidade de vida das pessoas ${ }^{2}$.

Neste sentido, éimportantequea SES, considerando seu atual papel no SUS, possa oferecer às SM S formulação política, cooperação técnica, planejamento e programação, cofinanciamento, desenvolvimento de recursos humanos e monitoramento eavaliação ${ }^{4}$. Para tanto, é preciso que o gestor estadual esteja atento às variáveis apontadas por $M$ atus ${ }^{13}$ para o bom gerenciamento: 0 projeto de governo, a governabilidadee a capacidade de governo de sua gestão.

\section{Considerações finais}

Com base no conteúdo discorrido neste artigo, pode-se concluir quea SES estudada encontra-se em um período de reorganização institucional, buscando se adequar às exigências do SUS, em especial ao processo de descentralização eredefinição das funções da esfera estadual.

Neste processo de reestruturação, a secretaria estadual de saúde tem enfrentado uma série de dificuldades relativas tanto à ausência de um projeto de governo, o que tem direta repercussão na direcionalidade da gestão, quanto a problemas de disponibilidade de recursos humanos e sua qualificação.

Com o componente III do Proesf foi possível problematizar junto com a SES em questão a necessidade de readequação técnica de seu quadro profissional. Da mesma forma, percebe-se a necessidade de projetos que trabalhem a gestão em Saúde Pública, permitindo às secretarias estaduais de saúde o melhor desempenho de suas novas responsabilidades anteo SUS. N este sentido, deveser salientada a relevância do Proesf para a construção de novos processos de trabalho e ampliação dos espaços de construção coletiva, com responsabilização de atores estratégicos.

Por fim, compreende-se que toda mudança é processual e contínua, eque para a efetivação da ampliação da capacidade de governo são necessárias a identificação dos problemas existentes e a implementação de estratégias. N este sentido, o presente artigo busca contribuir para este processo de mudança, apontando algumas dificuldades e, a partir delas, algumas recomendações:

1. Ampliação das capacitações técnicas dos profissionais, habilitando-os para suas funções, em especial em sistemas de informação e análise de indicadores de saúde;

2. Institucionalização de processos de planejamento estratégico;

3. Ampliação da capacidade técnica dos profissionais no uso "cotidiano" das ferramentas de avaliação;

4. Fortalecimento do Grupo Coordenador, incentivando o maior comprometimento dos atores envolvidos;

5. Continuação no Plano de Institucionalização do $M \& A$ da $A B$ - Proesf.

0 presente artigo fornece, assim, subsídios para a avaliação da gestão estadual, o que em última instância possibilita a tomada de decisão do gestor no planejamento e implementação de medidas que contribuam para o fortalecimento do papel das SES, buscando contribuir, desta forma, para a institucionalização do $M \& A$ da $A B$ e o fortalecimento do SUS.

\section{Colaboradores}

J Sampaio, EM F Carvalho, GFC Pereira e FM B $M$ ello participaram integralmente da pesquisa que deu origem ao presente artigo e de todas as etapas de sua elaboração. 


\section{Referências}

1. Cunha JPP, Cunha RE. Sistema Ú nico de Saúde: princípios. In: Brasil. Ministério da Saúde. Gestão municipal de saúde: textos básicos. Rio de Janeiro: M inistério da Saúde; 2001. p. 285-304.

2. Brasil. Ministério da Saúde. Secretaria de Assistência à Saúde. Regionalização da assistência à saúde: aprofundando a descentralização com equidade no acesso. Brasília: M inistério da Saúde; 2001.

3. Brasil. Conselho Nacional de Secretários de Saúde. Relatório Final do 1o Seminário para a construção dos consensos: preocupações e prioridades dos secretários estaduais de saúde quanto à organização, gestão e financiamento do SUS. Brasília: Conass; 2003.

4. Brasil. Conselho Nacional de Secretários de Saúde. A companhamento e avaliação da Atenção Primária. Brasília: Conass; 2004.

5. Brasil. M inistério da Saúde. Secretaria de Atenção à Saúde. Departamento de AB. Coordenação de Acompanhamento e Avaliação da AB. Proesf. [periódico na Internet]. 2005 [acessado 2005 set 20]. Disponível em: http://dtr2002.saude.gov.br/caadab/

6. Goldbaum M. Epidemiologia e serviços de saúde. Cad Saude Publica 1996; 12(Supl.2):95-98.

7. Matida AH, Camacho LAB. Pesquisa avaliativa e epidemiologia: movimentos e síntese no processo de avaliação de programas de saúde. Cad Saude Publica 2004; 20(1):37-47.

8. Contandriopoulos AP, Champagne F, Denis JL, Pineault R. A avaliação na área da saúde: conceitos e métodos. In: Hartz ZM A, organizador. Avaliação em saúde: dos modelos conceituais à prática na análise da implantação de programas. Rio de Janeiro: Editora Fiocruz; 1997. p. 29- 47.

9. Felisberto E. Avaliação do processo de implantação da estratégia da Atenção Integrada às Doenças Prevalentes da Infância (AIDPI) no Programa Saúde da Família (PSF) no estado de Pernambuco no período de 1998 a 1999 [dissertação]. Recife: Núcleo de Estudos em Saúde Coletiva do Centro de Pesquisas Aggeu Magalhães, Fiocruz; 2001.

10. Felisberto E. Monitoramento e avaliação na $A B$ : novos horizontes. Rev Bras Saúde M aterno-Infantil 2004; 4(3):317-321.

11. Cesar CLG, Tanaka OY. Inquérito domiciliar como instrumento de avaliação de serviços de saúde: um estudo de caso na região sudoeste da área metropolitana de São Paulo, 1989-1990. Cad Saude Publica 1996; 12(Supl.2):59-70.

12. Hartz ZM A, Pouvourville G. Avaliação dos programas de saúde: a eficiência em questão. Cien Saude Colet 1998; 3(1):68-82.

13. Matus C. Estrategia y plan. Santiago de Chile: Editorial Universitaria; 1972. p. 73-77.

14. Freese E, Sampaio J, Cesse E. Avaliação no Sistema Ú nico de Saúde. In: Augusto LG, Carneiro RM, $M$ artins PH. Abordagem ecossistêmica em saúde: ensaios para o controle da dengue. Recife: Ed. da UFPE; 2005. p. 54-64.

15. Freese E, Machado E, Cesse E. Analisando situações de governo em municípios pernambucanos: quem busca e quem produz mudanças na gestão do SUS. In: Freese E, organizador. Municípios: a gestão da mudança em saúde. Recife: Ed. da UFPE; 2004. p. 261-296.

16. Neves JL. Pesquisa qualitativa: características, usos e possibilidades. Cad Pesq Administração 1996; 1(3):1-5.
17. M inayo M C. O desafio do conhecimento: pesquisa qualitativa em saúde. 7ạ ed. São Paulo, Rio de Janeiro: Hucitec, Abrasco; 2000.

18. Bardin L. Análise de conteúdo. Lisboa: Edição 70; 1994.

19. Vieira SL, Hartz Z, Chaves S, Silva GA, Paim J. Análise da implantação da gestão descentralizada em saúde: estudo comparado de cinco casos na Bahia, Brasil. Cad Saude Publica 2007; 23(2):355-370.

20. Matus C. Adiós, señor presidente. Caracas: Editora Pomaire; 1987. p. 13-64.

21. Rivera U. Planejamento situacional: uma análise reconstrutiva. In: Gallo E, Rivera U, M achado M, organizadores. Planejamento criativo: novos desafios em políticas de saúde. Rio de Janeiro: RelumeDumará; 1992.

22. Rivera FJU. A gestão situacional (em saúde) e a organização comunicante. Cad Saude Publica 1996; 12(3):357-372.

23. Araújo JLJ, Maciel RF. Developing an operational framework for policy analysis. Rev Bras Saúde M aterno-Infantil 2001; 1(3):203-221.

24. Araújo JLJ. Health sector reform in Brazil, 1995-1998. A health policy analysis of developing health system [tese]. Leeds, UK: University of Leeds; 2000.

25. M atus $C$. El método PES: reingenieria pública y la teoria de las conversaciones: trabas y problemas. Caracas: Fondo Editorial Altadir; 1994. (Colección Ciências y Técnicas de Gobierno, n. 2).

26. Kopf ÁW, Hortale VA. A contribution from the Carlos $M$ atus management systems to communicative management. Cien Saude Colet 2005; 10(Suppl.):157-165.

27. Rivera U, Matus $C$, Testa M. Planejamento e programação em saúde: um enfoque metodológico. São Paulo: Cortez; 1989.

28. Bernadini TF, Barros SRL, Ferreira JHG. Planejamento em saúde. São Paulo: Faculdade de Saúde Pública da Universidade de São Paulo; 1998.

29. Brasil. M inistério da Saúde. Portaria no 373, de 27 de fevereiro de 2002. Aprova Norma Operacional da Assistência à Saúde-N oas/SUS 01/02. Diário Oficial da União 2002; 28 fev.

30. Toni J. 0 que é o planejamento estratégico situacional? Revista Espaço Acadêmico [periódico na Internet] 2004 [acessado 2004 set 25]; 32. Disponível em: http:/ /www.espacoacademico.com.br/032/32ctoni.htm

31. Bourdieu P. 0 poder simbólico. $4^{\mathrm{a}}$ ed. Rio de Janeiro: Bertrand Brasil; 2001.

32. Sampaio J. A construção de novas políticas públicas como caminho para a prevenção da Aids [tese]. Recife: Centro de Pesquisa Aggeu Magalhães, Fundação Oswaldo Cruz; 2006.

33. Brasil. Ministério da Saúde. Secretaria de Gestão do Trabalho e da Educação na Saúde. A educação permanente entra na roda: pólos de educação permanente em saúde - :conceitos e caminhos a percorrer. Brasília: M inistério da Saúde; 2005.

34. Branco MAF. Uso da informação em saúde na gestão municipal: para além da norma. In: Freese $\mathrm{E}$. M unicípios: a gestão da mudança em saúde. Recife: Ed. da UFPE; 2004. p. 77-90.

Artigo apresentado em 10/08/2007

A provado em 20/12/2007

Versão final apresentada em 03/06/2009 